\title{
Expectations and tasks of health care to reduce HIV/AIDS
}

\author{
Emmanuel J. Johnson
}

University of West Indies, Social Work Unit, Department of Behavioural Sciences, Faculty of Social Sciences, St. Augustine Campus, St. Augustine, Trinidad and Tobago

\begin{abstract}
Introduction: The government of Trinidad and Tobago considers that the enjoyment of the highest attainable level of health is a basic right of every citizen, and it has a goal to achieve health for all by 2025. Thus, it places emphasis on caring and assures standards of excellence to promote, protect, and improve the health status of the people of Trinidad and Tobago. To achieve these goals, it is very important to increase curative services as well as preventive services in the country.

Material and methods: Children born with human immunodeficiency virus (HIV) in Trinidad and Tobago are surviving, especially with free and increased access to antiretroviral therapy. This paper focuses on the role of health professionals to reduce and prevent the HIV/acquired immunodeficiency syndrome (AIDS) epidemic in Trinidad and Tobago. In view of this situation, there is a need to overcome the challenges of public health by involving community and individuals and self-reliance to prevent and reduce the HIV/AIDS epidemic.

Results: The author highlight the contribution of health professionals and the Public Health Policy, which remains an untapped resource within the community for addressing HIV/AIDS prevention and early detection.

Conclusion: Social workers are needed to address the individual needs of persons living with and affected by HIV/AIDS, and the needs of their families and communities, as well as to address the larger issues of social injustice that affects and is affected by the HIV pandemic.
\end{abstract}

HIV AIDS Rev 2019; 18, 3: 153-157 DOI: https://doi.org/10.5114/hivar.2019.88446

Key words: HIV/AIDS, health care, health policy, epidemic, Trinidad and Tobago.

\section{Introduction}

According to the World Health Organisation (WHO) [1], human immunodeficiency virus (HIV), the virus that causes acquired immunodeficiency syndrome (AIDS), is a retrovirus that infects the cells of the immune system, destroying or impairing their function [2]. The Ministry of Education of Trinidad and Tobago [3] says that HIV/AIDS is seen as

a global, social, health, and economic problem affecting all societies. After approximately three decades of this pandemic, the Ministry seriously took steps to prevent HIV/ AIDS. According to Jones et al. [2], HIV/AIDS made its way to the Caribbean in the early 1980s. The first AIDS case in the Caribbean was reported in Jamaica in 1982, and in 1983 eight persons were diagnosed with AIDS in Trinidad. HIV is transmitted by unprotected sexual intercourse, contaminated

Article history:

Received: 26.03.2019

Received in revised form: 04.06.2019

Accepted: 05.06.2019

Available online: 12.09.2019
International Journal of HIV-Related Problems

HIV \& AIDS Re vi e w 
blood used for blood transfusions, needles contaminated with HIV, prenatally, and by breastfeeding [4]. It is noted that in the Caribbean, the primary mode of transmission of the HIV virus is through heterosexual contact $[5,6]$, and the second most common is through drug injecting [7].

Drug injecting, in the spreading of HIV/AIDS, is described that the most evident problem caused by drug abuse. Sharing injecting equipment, whether the injection method is intravenous, intramuscular, or beneath the skin, carries a very high risk of transmission of HIV as well as other blood-borne infectious diseases such as hepatitis B and C [8]. The Caribbean is the second most affected region globally after sub-Saharan Africa to be impacted by HIV/ AIDS. The highest rates of HIV/AIDS have been reported among Caribbean countries with tourist-dependent economies [9]. Although Trinidad and Tobago is not considered one of these, Tobago's entry into the tourism industry has propelled that island into the mainstream of the HIV/AIDS crisis in the region [10]. Modelling studies suggest that meeting the 90-90-90 targets using current health technologies will enable the goal of ending HIV/AIDS by 2030 to be achieved, even without a therapeutic means of cure or a preventive vaccine [11].

\section{Overview of the HIV epidemic}

The most recent modelling of the available surveillance data for Trinidad and Tobago indicates a steady decrease in the HIV prevalence rates from 29,000 at the end of 2006 to 14,000 in 2009 . One of the main reasons for this decrease in prevalence is an advancement in the health care facilities and accessing the free anti-retroviral therapy made available by the Government of Trinidad and Tobago since 2002. Adimora et al. [12] indicated that societal-level changes can also help to arrest the HIV epidemic.

\section{Public health care}

The Government of Trinidad and Tobago developed a National Strategic Plan (NSP), which aimed to reduce the incidence of HIV infections in Trinidad and Tobago and to mitigate the negative impact of HIV/AIDS on persons infected and affected in the country $[10,13]$. This plan was implemented through sexual education programmes, life-skills development programmes, and other programmes that promote behaviour change among students, employees, and parents. Employee assistance, community mobilisation, access to health services, peer education, and financial and psychosocial support were strategies looked at by the Ministry of Education as ways that can be used to reduce the num- ber of persons being infected by HIV/AIDS in this country [13].

The Ministry of Health Trinidad and Tobago aims to prevent the HIV/AIDS epidemic along with the UNAIDS strategy to end the AIDS epidemic by 2030. As highly active antiretroviral treatment (HAART) becomes more widely available in Trinidad and Tobago there are an increasing number of babies born with HIV that are surviving to adolescence and adulthood. The availability of antiretroviral therapy has significantly increased the quality of life for this population; the fact is that their life expectancy has increased because of the committed contribution and care by caregivers, health care professionals, and social workers. Mofenson and Cotton [14] outline several challenges faced now that there are increasing resources available to manage the health of children infected with HIV at birth. These include maintaining adherence to lifelong therapy, the selection of successive antiretroviral regimens, and the limited availability of antiretroviral drugs designed for children. Additionally, this population has unanticipated needs such as the management of long-term complications of therapy, reproductive and sexual health, and the issue of higher education and career training. The HIV-positive child also has to transition from paediatric care settings to adult HIV care settings and assume responsibility for his or her own care.

Table 1 gives an estimate of all people (adults and children) alive at yearend with HIV infection, whether or not they have developed symptoms of AIDS. From the above statistics there is a decrease in people affected by HIV/AIDS. The country can achieve this and will continue to do so because of the various programmes and prevention methods adopted by the Health Ministry to eradicate this epidemic by 2030 .

\section{The response to HIV/AIDS and prevention of the epidemic}

There is a strong global consensus that the tools now exist to end the AIDS epidemic. This confidence is based on a combination of major scientific breakthroughs and accumulated lessons learned over more than a decade of scaling up the AIDS response worldwide. The achievement of targets built on these tools now needs to be fast-tracked. HIV treatment can dramatically extend the lifespan of people living with HIV and effectively prevent HIV transmission. There are also many proven opportunities for HIV prevention beyond medicines, including condom programming, behaviour change, voluntary medical male circumcision, and programmes with key populations. These have clearly demonstrated their capacity to sharply lower rates of new

Table 1. Statistics showing the decrease of HIV/AIDS in Trinidad and Tobago

\begin{tabular}{c|c|c|c|c|c|c|c|c|c|c}
\hline 2004 & 2005 & 2006 & 2007 & 2008 & 2009 & 2010 & 2011 & 2012 & 2013 & 2014 \\
\hline 29,000 & 29,000 & 29,000 & 29,000 & 29,000 & 14,000 & 14,000 & 15,000 & 15,000 & 15,000 & 14,300 \\
\hline
\end{tabular}


Table 2. Efforts taken to prevent, treat, care for, and support, to reduce HIV/AIDS

\begin{tabular}{|c|c|}
\hline Prevention & $\begin{array}{l}\text { - Heightened HIV/AIDS education and awareness. } \\
\text { - Improved availability and accessibility of condoms. } \\
\text { - Extended responsibility for the prevention of HIV to all sectors of government and civil } \\
\text { society. } \\
\text { - Introduced behaviour change intervention programmes targeted at young females. } \\
\text { - Introduced behaviour change interventions targeted at youths in and out of school. } \\
\text { - Supported behaviour change programmes targeted to MSM. } \\
\text { - Implemented a nationwide MTCT programme. } \\
\text { - Developed a comprehensive national VCT programme. } \\
\text { - Promotion of VCT services. } \\
\text { - Ensured the availability of adequate post-exposure services. } \\
\text { - Increased knowledge and awareness of the symptoms of STIs. } \\
\text { - Ensured effective syndrome management of STIs. } \\
\text { - Provided "youth-friendly" sexual and reproductive health services. }\end{array}$ \\
\hline Treatment, care, and support & $\begin{array}{l}\text { - Implemented a national system for clinical management and treatment of HIV/AIDS. } \\
\text { - Improved access to medication, treatment, and care for persons with opportunistic } \\
\text { infections. } \\
\text { - Provided appropriate economic and social support to PLHIV and to the affected. }\end{array}$ \\
\hline $\begin{array}{l}\text { Advocacy and } \\
\text { human rights }\end{array}$ & $\begin{array}{l}\text { - Promoted openness and acceptance of PLHIV in the workplace and in the wider community. } \\
\text { - Created a legal framework that protects the rights of the PLHIV and other groups affected } \\
\text { by HIV/AIDS. } \\
\text { - Monitored human rights abuses and implemented avenues for redress. } \\
\text { - Mobilised opinion leaders on HIV/AIDS and related human rights issues. }\end{array}$ \\
\hline $\begin{array}{l}\text { Programme management, } \\
\text { coordination, and evaluation }\end{array}$ & $\begin{array}{l}\text { - Developed an appropriate management structure for the national expanded response. } \\
\text { - Gained wide support for the NSP. } \\
\text { - Mobilised adequate and sustained resources to support implementation of the NSP. } \\
\text { - Monitored the implementation of policies and programmes as outlined in the NSP. } \\
\text { - Strengthened the key constituents of NACC. } \\
\text { - Strengthened support groups for PLHIV to better respond. }\end{array}$ \\
\hline
\end{tabular}

HIV infections. HIV programmes are dramatically strengthened when they are combined with social and structural approaches; for example, a recent analysis concluded that this could reduce new HIV infections among sex workers by a third or more. HIV infections may not disappear in the foreseeable future, but the AIDS epidemic can be ended as a global health threat. The number of new HIV infections and AIDS-related deaths will need to decline by $90 \%$ compared to 2010 [15]. Reduction of infectious diseases can probably be traced to the availability of drugs that have cured, masked, or delayed the onset of final illness or at least treated the worst symptoms of the diseases [16]. Table 2 clearly shows the efforts taken by the Ministry to prevent, treat, care for, and support, to reduce HIV/AIDS, which has yielded good results.

\section{HIV prevention measures, risk-reduction, and management}

\section{Improved treatment facilities}

In recent years, the use of protease inhibitor (PI) combination therapies has led to a significant decline in opportunistic infections, hospitalisation rates, and AIDS-related deaths [17]. Protease inhibitor combination therapies have significantly improved the health of many people with HIV/AIDS. AIDS is a less serious threat nowadays, and being HIV-positive not such a a big deal. Another reason for the decrease in HIV/AIDS infection is because of greater awareness about safer sex.

\section{Health policy on protection}

Caribbean Guidelines for the Care and Treatment of Persons with HIV Infection outline treatment and procedures for children infected with HIV at birth and gives guidelines for antiretroviral therapy as the children develop. However, these guidelines do not cover the issues associated with transitioning from paediatric care to adolescent and adult care that would arise as the individual grows older. These issues include the individual's ability to manage his or her own care, leaving a familiar health care setting, psychosocial and developmental challenges, and challenges within the health care system [18]. These dynamics should be an integral part of care planning for persons born with HIV and those infected with the virus at a young age.

HIV-positive women who take antiretroviral medication during pregnancy can reduce the risk of transmitting the vi- 
rus to their children to less than one per cent, and the instances in which infants are infected are associated with interruptions of care at some point during the pregnancy. Additionally, HIV prevention strategies for women and girls, especially those of childbearing age, need to be implemented and continuously monitored and evaluated. In the event that a baby is born with HIV, intervention with both mother and child should be done at birth or in the early stages of the child's development, so that the child can understand his/ her medical condition, and adjust and manage the condition as he/she grows older. In Trinidad and Tobago children born of HIV-positive mothers are given a one-year supply of baby formula to reduce the risk of transmission from mother to child during breastfeeding. HIV-positive mothers who qualify need to receive financial assistance to provide for the nutritional needs of their children after the age of one year in order to reduce the risk of the child becoming infected at a young age.

\section{Point of care testing}

Point of Care Testing (POCT) is defined as testing at or near the site of patient care. The driving notion behind POCT is to bring the test conveniently and immediately to the patient. This increases the likelihood that the patient will receive the results in a timely manner. POCT is accomplished through the use of transportable, portable, and hand-held instruments that are cheaper, smaller, and faster with the same accuracy as the larger Laboratory Analysers. To this end, the Ministry of Health in collaboration with the South West Regional Health Authority (SWRHA) has evaluated most of the POCT equipment on the market and have chosen the latest and most accurate of analysers to use in our POCT program. These analysers can also feed information via the laboratory information system set up throughout the SWRHA. Self-testing is also emerging as a useful and potentially supplementary way to increase the proportion of people who know their HIV status [19].

\section{The Post-Exposure Prophylaxis Policy}

The Post Exposure Prophylaxis Policy is implemented within the context of all other HIV policies, including the policy on the Decentralisation and Integration of HIV Services. This Policy is implemented by the RHAs at their points of care and monitored by the $\mathrm{MOH}$. It relies on trained and professional personnel, who are able and empowered to administer PEP; a strong supply chain that ensures a reliable supply of antiretroviral drugs; support services for persons exposed to the HIV/AIDS virus, including counselling; and monitoring and evaluation to ensure the delivery of quality PEP services.

The contributions of HIV counselling and testing centres that offer HIV counselling and testing upon admittance. All pregnant women who test positive should be encouraged to disclose their status to their partners and to have their partners tested. Health care providers are also encouraged to counsel patients on risk reduction and to refer them for appropriate social and psychological support. The HIV/AIDS Coordinating Unit is providing a comprehensive, coordinated approach and leadership to all stakeholders involved in the health sector response to HIV/AIDS. It coordinates, advises on policy direction, and monitors and evaluates the implementation of the Ministry of Health's response to the HIV epidemic.

Health sector workers who know or have good reason to believe that an HIV infected worker is practicing in a way that places patients at risk, or has done so in the past, must inform the worker's immediate supervisor. Wherever possible, the health care worker should be informed before information is passed to a supervisor. HIV infected or affected health care workers must not rely on their own assessment of the risk they pose to patients. A health care worker who has any reason to believe they may have been exposed to HIV infection, or a healthcare worker who has engaged in high-risk behaviour as it relates to HIV, in whatever circumstances, must promptly seek and follow confidential professional advice on whether they should be tested for HIV. Failure to do so will breach the duty of care to patients. Workers and their representatives should advocate for and collaborate with employers to maintain a safe and healthy working environment.

\section{Conclusion}

Health professionals have become increasingly involved in the prevention and treatment of HIV/AIDS disease since its emergence nearly three decades ago. Social workers are needed to address the individual needs of persons living with and affected by HIV/AIDS, the needs of their families and communities, and to address the larger issues of social injustice that affect and are affected by the HIV pandemic. According to Natale et al. [20], to succeed, social workers must adopt a global perspective. Through the National Strategic Plan and the Health Sector Plan, the Ministry of Health is committed to reducing of the spread of HIV. The social work profession remains an untapped resource within the community for addressing HIV/AIDS prevention and early detection. Appointment of more social workers and other Para Medical professionals within the community will support the Ministry to reduce HIV/AIDS.

\section{Research involving human participants and/or animals}

All procedures performed in studies involving human participants were in accordance with the ethical standards of the institutional and/or national research committee and with the 1964 Helsinki declaration and its later amendments or comparable ethical standards. 


\section{Conflict of interest}

The author declares no potential conflicts of interest with respect to the research, authorship, and/or publication of this article.

\section{References}

1. World Health Organization. Health topics, Online question and answers, what is HIV? 2017. Available at: https://www.who.int/features/qa/71/en/

2. Jones V, Modeste N, Hopp Marshak H, Fox C. The effect of HIV/ AIDS education on adolescents in Trinidad and Tobago. ISRN Infectious Diseases 2013; 1: 1-8.

3. Ministry of Education. Republic of Trinidad and Tobago. Education Sector Policy of HIV and AIDS of the Ministry of Education. 2008.

4. Patrice-Coy C, Johnson EJ, Boodram ChAS. Sexual behaviour of female adolescents on the spread of HIV/AIDS and other STDs in Carriacou. Medicine (Baltimore) 2016; 95: e4800.

5. Johnson EJ. A case study on the consequences of HIV/AIDS within the Caribbean: issues faced by a teenager born with HIV. HIV AIDS Rev 2018; 17: 152-157.

6. St. Lawrence JS, Crosby RA, Brasfield TL, O’Bannon III RE. Reducing STD and HIV risk behavior of substance-dependent adolescents: a randomized controlled trial. J Consult Clin Psychol 2002; 70: 1010-1021.

7. UNDP. Global commission on HIV and Law, Risks, Rights and Health. UNDP, HIV/AIDS Group, Bureau for Development Policy, New York 2012. Available at: https://www.undp.org/content/dam/ undp/library/HIV-AIDS/GovernanceofHIVResponses/Commissionsreportfinal-EN.

8. UNAIDS. Joint United Nations Program of HIV/AIDS. UNAIDS, Geneva 1997. Available at: www.unaids.org.

9. Baird DS, Yearwood EL, Perrino CS. Small islands, big problem: HIV/AIDS and youth in Trinidad and Tobago. J Child Adolesc Psychiatr Nurs 2007; 20: 243-251.

10. Johnson EJ, Rodrigues V. Primary health care: expectations and tasks for public health in Trinidad and Tobago. J Community Health 2016; 41: 645-649.

11. UNAIDS. 90-90-90. An ambitious treatment target to help end the AIDS epidemic. UNAIDS, Geneva 2014.

12. Adimora AA, Schoenbach VJ, Floris-Moore MA. Ending the epidemic of heterosexual HIV transmission among African Americans. Am J Prev Med 2009; 37: 468-471.

13. Ministry of Education, Trinidad. Ministry of Education policy on HIV/AIDS in Trinidad and Tobago. 2008. Available at: https:// hivhealthclearinghouse.unesco.org/library/documents/ministry -education-policy-hivaids-education.

14. Mofenson LM, Cotton MF. The challenges of success: adolescents with perinatal HIV infection. J Int AIDS Soc 2013; 16: 18650.

15. UNAIDS. Fast-Track - Ending the AIDS epidemic by 2030. 2014. Available at: Retrieved from http://www.unaids.org/sites/default/files/ media_asset/JC2686_WAD2014report_en.pdf (Accessed: 5.12.2016).

16. Macintyre $\mathrm{K}$, Macdonald C. Implementing tuberculosis control in Scotland (1945-1960): overcoming stigma at the community level. Welcome Trust Unit of the History of Medicine. Glasgow University, Working Paper Series 2000.

17. Demmer C. Impact of improved treatments on perceptions about HIV and safer sex among inner-city HIV-infected men and women. J Community Health 2002; 27: 63-73.

18. Columbia University. Supporting the Transition to Adult Care. 2014. Available at: http://files.icap.columbia.edu/files/uploads/Module_13_-_PM_Adolescent.pdf (Accessed: 16.11.2015).
19. MacPherson P, Lalloo DG, Webb EL, et al. Effect of optional home initiation of HIV care following HIV self-testing on antiretroviral therapy initiation among adults in Malawi: a randomized clinical trial. J Am Med Assoc 2014; 312: 372-379.

23. Natale AP, Biswas B, Urada LA, Scheyett AM. Global HIV and AIDS: calling all social work educators. Social Work Education 2010; 29: 27-47. 